\title{
A Model-driven Framework for Educational Game Design
}

\author{
Bill Roungas \\ TU Delft, The Netherlands, \\ V.Roungas@tudelft.nl
}

\begin{abstract}
Educational games are a class of serious games whose main purpose is to teach some subject to their players. Despite the many existing design frameworks, these games are too often created in an ad-hoc manner, and typically without the use of a game design document (GDD). We argue that a reason for this phenomenon is that current ways to structure, create and update GDDs do not increase the value of the artifact in the design and development process. As a solution, we propose a modeldriven, web-based knowledge management environment that supports game designers in the creation of a GDD that accounts for and relates educational and entertainment game elements. The foundation of our approach is our devised conceptual model for educational games, which also defines the structure of the design environment. We present promising results from an evaluation of our environment with eight experts in serious games.
\end{abstract}

Keywords: educational game design, game design document, model-driven framework;

\section{Introduction}

According to Zyda [1], a serious game is "a mental contest, played with a computer in accordance with specific rules, that uses entertainment to further government or corporate training, education, health, public policy, and strategic communication objectives". Educational games are a class of serious games having an educational/learning purpose in the context of primary or secondary school, higher education, etc.

Despite the recent traction that serious games gained, thanks to the increasing usage by parents and teachers [2], and despite all the available technologies, the design process of these games have not changed significantly, and still largely relies on tools such as simple text editors and prototyping software systems [3].

Moreover, the usefulness of game design documents (GDDs) as design artifacts is being questioned. A recent survey by Sundström [4] shows that less than 50\% of game professionals believe that GDDs are an effective way to communicate the design of a game, and only $5 \%$ read GDDs to analyze a specific aspect of game design.

In this paper, we propose an approach that aims to make GDDs a useful artifact. Our hypothesis, also supported by Sundström's [4] research, is that GDDs are either hardly or inefficiently used due to a variety of reasons:

- Inconsistency [5]: the same concepts are documented using different terminology in the GDD, and some design decisions are conflicting.

- Infrequent updates [5]: after the initial stages, the GDD is not updated regularly.

- Multiple communication means: Bethke [6] identified three different ways of communication in a gaming company, a) through an explicit GDD, b) through digital means (emails, Skype, wikis, etc.), and c) oral. Using multiple ways to communicate can potentially lead to communication loss or overload.

- Heterogeneous users. GDDs are used by professionals with different educational and/or professional background, like artists and programmers. This leads to high chances of different interpretations of the same text.

The solution that we propose is based on the construction of a conceptual model [7] of educational games that describes its main constituents and their relationships. Such model defines the structure of the GDD and provides a common ground for communication among 
heterogeneous stakeholders. We also present a model-driven, web-based environment that enables the creation of GDDs that align with our conceptual model. Specifically, we make the following contributions:

1) Based on our study of the literature, we identify and relate the elements of educational games into a conceptual model for the design of educational games.

2) We describe the main features of our web-based, model-driven design environment that can be used for building GDDs for educational games.

3) We report on a qualitative evaluation of our environment with eight experts in serious games (design), which aims to assess the perceived usefulness of our solution.

The rest of the paper is structured as follows. After reviewing the literature in Section 2, we introduce the conceptual model in Section 3, and we present the web environment in Section 4. We discuss the results from the evaluation in Section 5, and conclude in Section 6.

\section{Background Work}

In this section, we review previous work in the field of educational games. Our research method is as follows: we first decompose educational games into their primitive components, start the research from these components and gradually research each level of abstraction until we reach the end product; the educational games.

Figure 1 below shows the different abstraction levels of educational games and on which areas of research they led us.

Although our research does not cover all the work that has been done on each of the fields analyzed, it is representative of the current state-of-the-art.

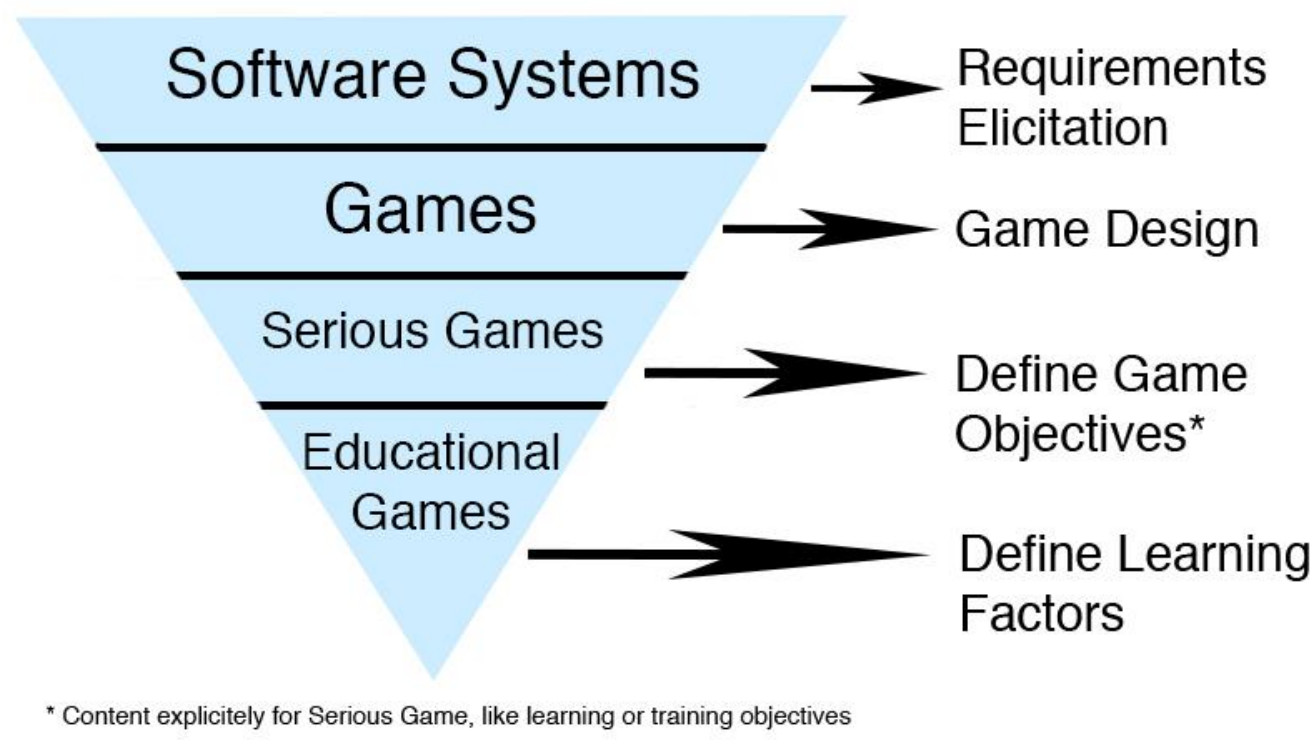

Figure 1. Abstraction levels of educational games

Based on this decomposition of educational games, we split our research in five main pillars. First, we research the factors that influence learning. Second, we research theories on entertainment with the goal to identify elements that provoke fun and generally feelings of enjoyment. Third, we identify the core game elements based on the academic research on the field and we cross referenced the results with a typical Game Design Document. Fourth, we research the state-of-the-art on requirements and requirements elicitation on creative fields, like games. Fifth, we search for techniques used in game design and more specifically for techniques that are applicable on serious and educational games. 


\subsection{Learning}

We analyze some characteristics that most of the pedagogues believe that influence learning in a positive way:

- Readiness for learning, which means that a person should be ready to learn something before he or she actually learns it. Readiness for learning is influenced by the Age [8] [9], Prior knowledge [10], Talent [11], and Willingness.

- Motivation. It is very important for teachers and parents to motivate children, at least to the point where they will be able to be self-motivated. The effectiveness of motivation is influenced by the Usefulness [8], Environment (Family, School, Society) [12], Type (Intrinsic, Extrinsic) [13] [14], and Time (Short-term, Long-term).

- Repetition. The repetition of reactions to stimuli is called exercise. Learning rarely can be accomplished by the first reaction to a stimulus. Several reactions or answers are needed. The effectiveness of repetition is influenced by the Frequency [15], Content (Identical, Modified), and Intention (Learning, Punishment).

- Stimulus. According to Pavlov [16], a stimulus that is accompanied by a reaction helps learning. The effectiveness of stimuli is influenced by the Type (Vision, Audition, Gustation, Olfaction, Somatosensory), Duration, Intensity, Lucidity, Collective Consciousness [17], and Fantasy [18].

- Reward \& Punishment. Rewarding a child after or even before learning something is important, in order for this child to link learning with something pleasant. The effectiveness of both reward and punishment is influenced by the Age, Type, Time, and Frequency.

\subsection{Entertainment}

The primary purpose of games is to entertain users. But what are the individual elements that provoke entertainment? According to Aristotle [19], in order to hold an audience's attention, the creator(s) of a public presentation, e.g. a play or a game, must design their presentation thoroughly, based at least on one of the following attributes:

- Plot. Defined as the scenario or storytelling.

- Character. Defined as the character presentation and evolution.

- Meaning. Defined as the intellectual stimulation.

- Dialog. Defined as dialogs that are memorable.

- Music. Defined as the music that enhances a play or a game.

- Spectacle. Defined as an exciting and spectacular visual presentation.

According to Malone [20], in order for something, either a play or a game, to be entertaining, it should provoke fantasy; defined as the mental images evoked by the user through the game environment, and/or curiosity. Curiosity was later also researched by Garris et al. [21] and renamed to Mystery. According to Garris et al. [21], mysteries presented in a game can evoke curiosity in the individual, pushing a desire for discovery.

Garris et al. also proposed that Sensory Stimuli is a key element for entertainment, since stimulating our senses leads to stronger motivation. Finally, Csikszentmihalyi [14], through his work about the theory of Flow, noticed that diminishing the extraneous distractions causes increased concentration, which facilitates flow and entertainment.

\subsection{Game design elemets}

A game, apart from the more generic entertaining elements described in the previous section, also incorporates several game-specific characteristics:

- Rules. Rules limit the players' actions and describe how the game works [22].

- Goals. Goals are necessary in games for player to judge their performance [20] and to motivate them.

- Challenges. Challenges must be carefully designed, in order not to be too boring or too difficult to accomplish. The balance between skills and challenges, described by Csikszentmihalyi [14], is depicted on the Figure 2.

- Feedback. Feedback should be clear and on time, regarding player's performance. 


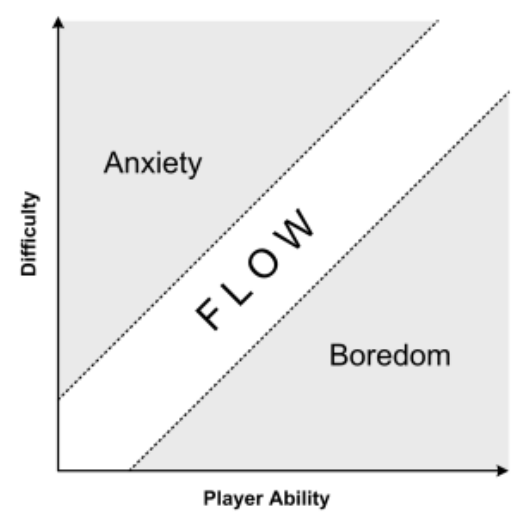

Figure 2: The diagram of optimal flow according to Csikszentmihalyi

Finally, reading Baldwin's [23] GDD helped us identify one more element of games; Levels, which was not present into the literature. In Section 3, we show the importance of levels and their relationship with the knowledge an educational game aims at conveying.

\subsection{Requirements}

In the area of requirements engineering, several researchers have proposed ways to integrate, quantify and visualize creativity and emotions on games.

Callele et al. [29] identify the need to extend traditional requirements engineering techniques to support the creative process in video game development. Their proposal is to better balance the time spend on a project between the pre-production and the production phase and to add gameplay requirements, which are unique to video games, to the requirements engineering process. Callele et al. [30] also managed to capture and express emotional requirements by introducing visual mechanisms, like emotional terrain maps, emotional intensity maps and emotion timelines. Visualizing emotions enables to link emotions to spatial qualifiers and thus help designers to better understand which elements and where in the game cause certain emotions.

Draper [31] agrees that fun should be taken as a requirement when designing games but he argues that fun is the only kind of enjoyment that provokes, what he identified as, u-flow (unconscious flow) and c-flow (conscious flow). Hence, he believes that game designers should take into account other kind of enjoyment as well.

\subsection{Game design frameworks}

The Design, Play and Experience (DPE) framework [24] extends the Mechanics, Dynamics, Aesthetics (MDA) framework [25] (for designing entertainment games) for the design of serious games. DPE has four layers of components, one of which is MDA. Each layer has one subcomponent for each of the three pillars of DPE, meaning the Design, the Play, and the Experience. The contribution of DPE is the methodology it proposes in order to analyze and process the design of serious games, which when combined with an agile design environment, it provides a solution applicable to the whole spectrum of serious games.

The Serious Game Design Assessment (SGDA) framework [26] takes a similar standpoint, and defines six main aspects for the design of a serious game that shall be successfully combined to achieve the game's purpose: content, aesthetics/graphics, fiction/narrative, mechanics, framing, and interaction.

The LEGADEE online authoring environment [3] guides designers through multiple toolbars that support different design roles. The approach is model-driven, and is realized through an online environment. LEGADEE's intention is to offer a methodology and tools to guide the various actors that participate in the learning game conception, such as clients, teachers, game designers and developers. Our approach shares the same spirit with LEGADEE, but focuses on educational games.

Amory et al .[27] conducted an experiment on twenty students aiming at identifying which game type is more suitable depending on the learning environment and which are the game elements that students find interesting or useful. Results showed that the preferred genres are the $3 \mathrm{D}$ adventure and strategy games, whereas the game elements that students identified as the most 
useful were logic, memory, visualization and problem solving. Based on the results from the experiment, the authors presented a model that links pedagogical issues with game elements.

Aleven et al.[28] propose a design framework that requires the aligned definition of three main aspects, always keeping in mind that educational games need to be both educational and fun:

Learning Objectives: they are identified and defined by answering three questions:

What is the required prior knowledge?

What is the knowledge that players will acquire from the game?

What potential knowledge players can learn that goes beyond the scope of the game?

MDA [25]: this is used for designers need to define the mechanics and to influence the dynamics and the aesthetics of the game.

Instructional Principles, that define how the learning process will be conducted.

\subsection{Conclusion of the literature review}

The results of the literature illustrated in Sections 2.1, 2.2, 2.3, and 2.4 are the building blocks of the conceptual model we present in the next section. Table 1 summarizes the identified elements from our study in the literature.

Table 1. Educational game design elements

\begin{tabular}{|c|c|c|}
\hline Element & Research Domain & Source \\
\hline Plot & Entertainment & Literature \\
\hline Character & Entertainment & Literature \\
\hline Meaning & Entertainment & Literature \\
\hline Dialog & Entertainment & Literature \\
\hline Music & Entertainment & Literature \\
\hline Spectacle (Visual) & Entertainment & Literature \\
\hline Fantasy & Entertainment & Literature \\
\hline Mystery/Curiosity & Entertainment & Literature \\
\hline Concentration & Entertainment & Literature \\
\hline Rules & Gaming & Literature \\
\hline Challenges & Gaming & Literature \\
\hline Goals & Gaming & GDD \\
\hline Levels & Gaming & Literature \\
\hline Feedback & Gaming & Literature \\
\hline Readiness for Learning & Learning & Literature \\
\hline Motivation & Learning & Literature \\
\hline Repetition & Learning & Literature \\
\hline Stimulus & Learning & Literature \\
\hline Reward/Punishment & Learning & Literature \\
\hline
\end{tabular}

Our research is motivated by the fact that the existing frameworks, presented in Section 2.5, are rather high-level, as they include abstract elements as opposed to concrete ones that can serve 
as a basis for a design environment. For example, many of these approaches use the term "Learning" without going deeper into the core elements that define learning. The next section will address this limitation by proposing a detailed conceptual model. Moreover, with the exception of LEGADEE, none of the frameworks has been translated into a design environment, and they serve mostly as guidelines.

\section{Conceptual model}

In this section, we describe how we combine research from different domains into a conceptual model that defines the core elements of educational games. Our aim is to tackle the inconsistency problem of GDDs, for the conceptual model guides the design of educational serious games by providing a common ground that should minimize misunderstandings by defining a standard terminology to be adopted.

The main challenge in this endeavor is how to combine the entertaining and gaming aspects with the educational aspects. To such extent, we started a new study of the literature, and we paid particular attention to the findings related with the interconnections between the domains. By doing so, we managed to identify relationships among elements of different domains, which enabled us to start constructing the conceptual model.

\subsection{Relationships among elements}

Our aim is to build a combined model as opposed to a simple merging of two or more independent models. Hence, our next step was to identify the relationships between those elements. During our research, we defined the:

- Form of the relationship between several elements, but always between two elements at a time, which in most cases was accomplished by the use of a verb. E.g. Fantasy enhances Motivation.

- Cardinality of each relationship, whenever it was possible. Meaning how many elements of the Source Element are or can be related to the Destination Element. E.g. 1...n (one or more) Goals define Challenge.

Our research method on identifying the relationships was done on two steps:

1. We identified relationships through the literature, shown on Table 2, which provided a theoretically more solid background on our results.

2. We identified relationships not found in the literature, shown on Table 3, for which we give a detailed description of our rationale.

Table 2. Relationships between elements identified in the literature

\begin{tabular}{|c|c|c|c|c|}
\hline Source Element & Relationship & $\begin{array}{l}\text { Destination } \\
\text { Element }\end{array}$ & Cardinality & Reference \\
\hline Characters & participate in & Dialog & 2 & [37] \\
\hline Music & provokes & Stimulus & 1 & {$[38]$} \\
\hline Spectacle & provokes & Stimulus & 1 & [39] \\
\hline Fantasy & provokes & Curiosity/Mystery & & {$[40]$} \\
\hline Fantasy & enhances & Motivation & & {$[40]$} \\
\hline Fantasy & enhances & Challenge & & {$[20]$} \\
\hline Spectacle & enhances & Challenge & $1 \ldots n$ & {$[20]$} \\
\hline Curiosity/Mystery & provokes & Challenge & & [41] \\
\hline Stimulus & enhances & Fantasy & $0 . \ldots n$ & [32] \\
\hline Reward/Punishment & define & Challenge & $1 \ldots \mathrm{n}$ & {$[33]$} \\
\hline
\end{tabular}




\begin{tabular}{c|c|c|c|c}
\hline Challenge & define & Goal & $1 \ldots \mathrm{n}$ & {$[34]$} \\
\hline Feedback & provokes & Concentration & & {$[14]$} \\
\hline Motivation & provokes & Concentration & & {$[35]$} \\
\hline Curiosity/Mystery & influences & Motivation & & {$[35]$} \\
\hline Repetition & influences & Motivation & & {$[36]$} \\
\hline
\end{tabular}

Table 3. Relationships between elements not identified in the literature

\begin{tabular}{c|c|c|c}
\hline Source Element & Relationship & Destination Element & Cardinality \\
\hline Stimulus & enhance & Curiosity/Mystery & $0 \ldots 5$ \\
Rule & define & Challenge & $1 \ldots \mathrm{n}$ \\
\hline Readiness for Learning & influences & Meaning & \\
\hline Readiness for Learning & influences & Challenge & \\
\hline Goal & define & Level & $1 \ldots \mathrm{n}$ \\
\hline
\end{tabular}

Stimulus enhance Curiosity/Mystery: Audio, visual and tactile stimulation create a sense of curiosity on the players when the reason of the stimulus is not obvious. E.g. If players hear a sound that is intriguing but the source of the sound is not visible, or known, it is probable that they will be encouraged to discover where the sound came from, which enhances their curiosity and imparts an element of mystery.

Rule define Challenge: This is a two-way relationship. Rules, like physics rules or game rules, define how challenges are built. Seeing this relationship the other way, if designers want to design a challenge must adjust the rules associated with it. E.g. If gravity, as we know it, is part of the rules then the designer cannot design a challenge where the player will have to fly.

Rules limit the players' actions and describe how the game works [22] $\square$. According to the three dimensions of gameplay [42], one dimension is the challenge-based immersion, which is based on interaction and it includes the completion of goals and the acquirement of abilities. Rules define how the game works, which includes how to complete the goals and how to acquire abilities. Given all of the above, we can state that rules define challenge. In other words, a challenge has to be set first before the rules, which the designer wants to work alongside the challenge, are put into place. Bottom line, a challenge cannot function without rules.

Readiness for Learning influences Meaning: Readiness for learning, meaning the age and the level of knowledge of each player, influences not only the general idea but also the intellectual stimuli of the educational game. E.g. The intellectual stimuli of an educational game aimed at 6 year-old children will be significantly different from a similar game aimed at 14 year-old children.

Readiness for Learning influences Challenge: Equivalently, the way the challenges are designed, both in an intellectual and in a practical level, is influenced by the age and the prior knowledge of the players, whom these challenges are designed for.

Goal define Level: Each level requires from the players to complete certain goals, defined by the designer. A level can include one or more goals depending on its purpose. E.g. In an educational game about mathematics, a level about addition can have as goals: 1 . Answer correctly at least 10 questions, 2. Collect at least 100 coins, etc.

On the assembled conceptual model, shown in Figure 5, for simplification and readability purposes, only the most important relationships are depicted. But before going straight to the complete conceptual model, we describe its basic components.

\subsection{Basic components of the conceptual model}

Figure 3 shows how a game consists of game content elements that represent its structural components; game design elements that explain the choices of the designers in terms of mechanics, goals, etc.; and desired cognitive outcomes that the game aims to trigger in the players. Among the cognitive outcomes that are to be evoked in the player, important ones are fantasy [20], 
mystery and curiosity [21], and concentration [14]. Moreover, on Figure 3, it is shown that an educational game is a subclass of a game and as such it inherits one or more of its characteristics.

An educational game, apart from inheriting one or more of the characteristics of traditional games, is a type of game (see the is-a relationship) that aims at learning and does so by including a curriculum of knowledge to be transferred to the players (Figure 4). The curriculum is defined in terms of learning outcomes for the game [21] that define what knowledge the player is expected to achieve.

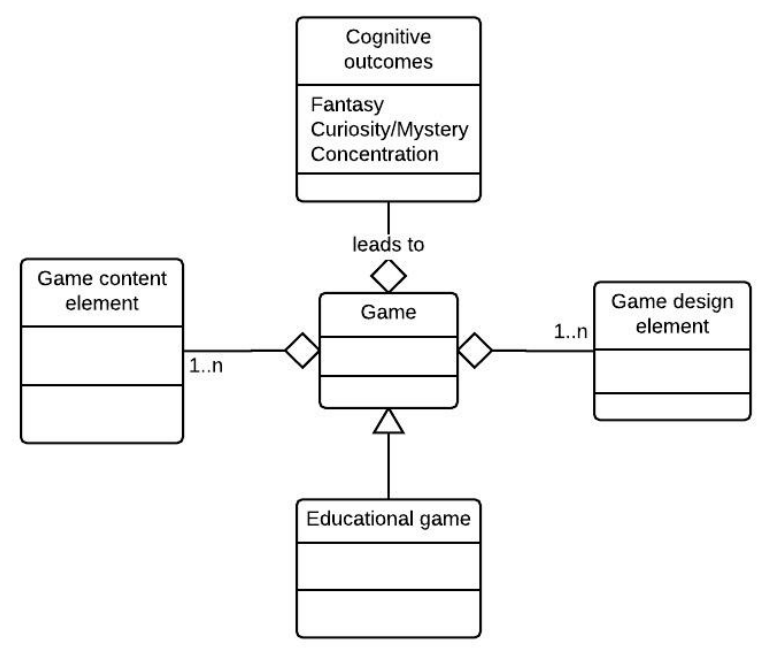

Figure 3. A game's subclasses

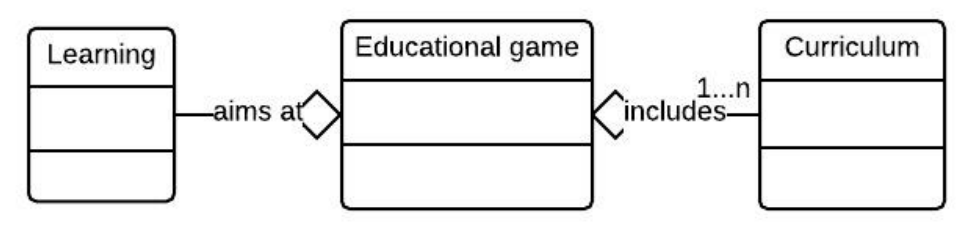

Figure 4: An educational game

\subsection{The conceptual model}

In more detail, as far as game contents are concerned, we refer back to Aristotle's work [43], who defined the key dramatic elements to hold the attention of the audience as: well-defined, evolving characters; a meaning that stimulates intellect; dialogs that are memorable; music (or audio in videogames) that enhance the auditory experience; and spectacle to stimulate the visual experience.

Several game design elements are necessary to coordinate the dramatic elements $\backslash$ into a genuine gaming experience: goals that the players shall strive for [23], game mechanics that determine the gameplay and constrain the possible behavior [22], increasingly hard challenges that keep the player engaged within a flow experience [14] (challenges are also part of the three dimensions of gameplay [42]), levels that split the game into multiple smaller episodes [23], and feedback that provides an immediate reaction on the players' actions [14].

Our conceptual model details the main factors that affect the learning process. In the first place, learning requires that the learners/players have an adequate readiness for learning [10] in terms of age, talent, prior knowledge, and environmental factors: an excellent instructional method would not work when a misfit with the audience exists. Moreover, learning is affected by a number of influencing factors: the motivation [44] of the learner, the use of repetition to boost learning effectiveness [45], the provision of stimuli [18], and the inclusion of rewards/punishments [46] in response to positive and negative learning behaviour. 
A key chunk of the conceptual model is that relating level and learning outcome: every level requires the achievement of learning outcomes, delivers other outcomes, and tests outcomes as well. This structure enables defining an order relationship among levels in educational terms: a level that requires a certain learning outcome shall appear in the game only after a level that delivers such outcome has been successfully played.

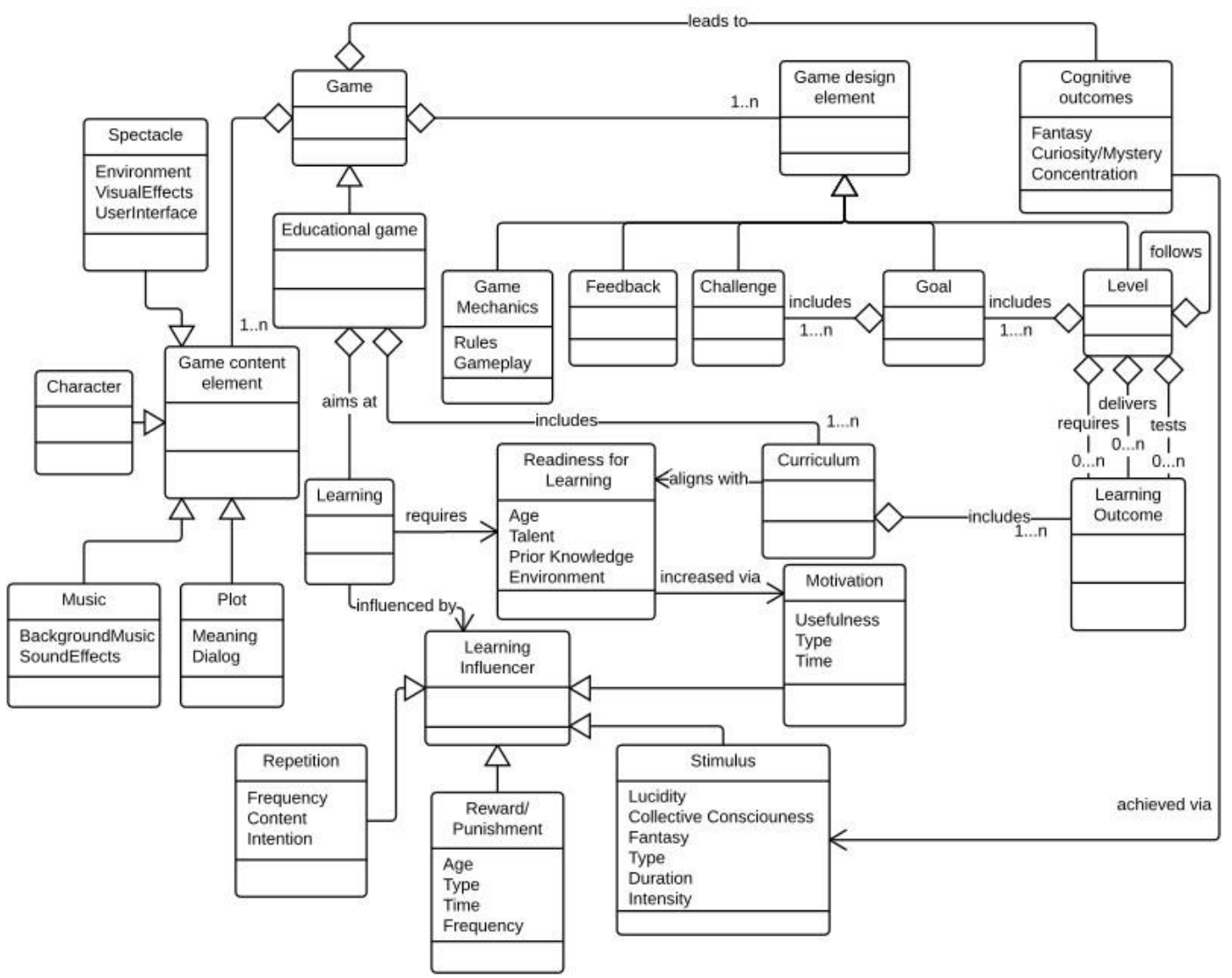

Figure 5. Conceptual model of educational serious games

\section{Design Tool}

The conceptual model is put in practice through the design and development of an ad-hoc, webbased, model-driven environment for the design of educational games 1 . In other words, the environment is aligned with the conceptual model in terms of the fields that are required to specify an educational game. Model-driven approaches have the advantage of being language independent [47]: the conceptual model can be used independently and contribute on building an environment with any programming language. As such, one could reuse the conceptual model to develop her own environment.

\subsection{Web-based}

Web applications provide several advantages that help overcome some of the problems associated with GDDs: (i) they are accessible from everywhere and from multiple users; (ii) the look and feel can be easily customized ; (iii) they can be accessed from a variety of devices; (iv) in comparison to desktop environments, they can achieve greater levels of interoperability.

1 http://seriousgamesdesign.com/Educational Framework/ 


\subsubsection{Technical Realization}

We developed the environment using some of the most commonly used web programming languages. We used PHP for the backend, Javascript, along with HTML and CSS, for the frontend, and AJAX for the asynchronous interaction of the users with the environment. The main reason for using AJAX is because through Ajax, it is possible to send and retrieve data from the server in the background without interrupting the functionality (both in display and behavior) of the displayed page, hence the designer can remain focused on building the game.

Figure 6 shows how we implemented AJAX on our environment to enable designers to quickly edit previously created objects.

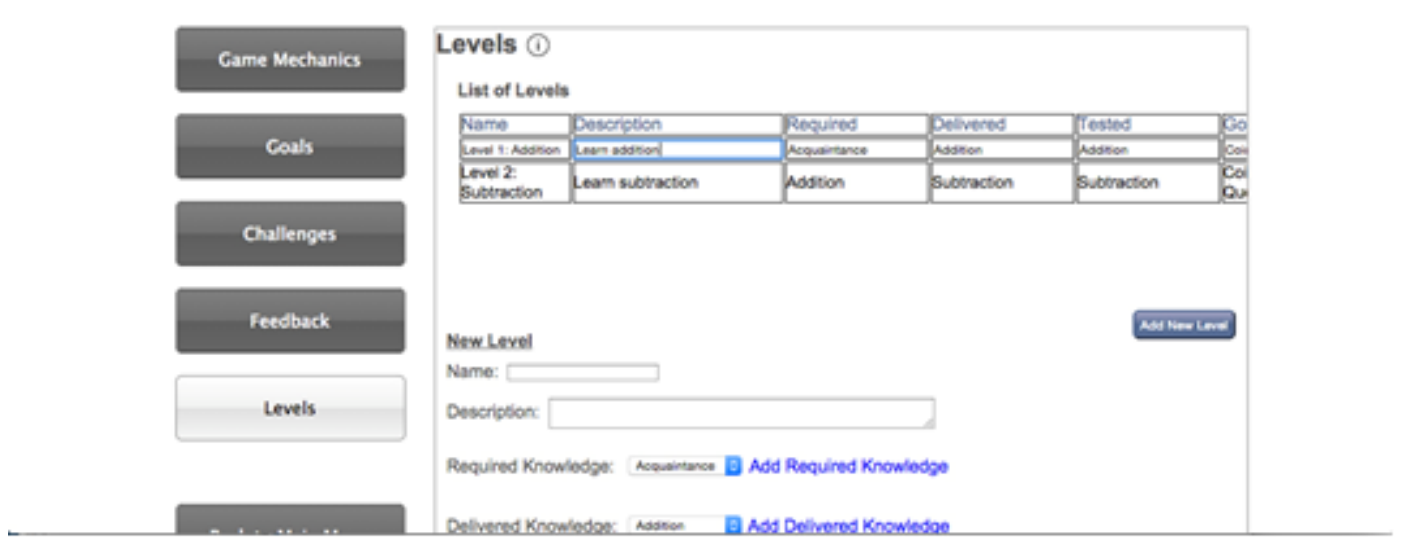

Figure 6. Using AJAX to edit the list of Levels without reloading

\subsubsection{Architecture}

The software architectural pattern that we used was the Model-View-Controller (MVC) pattern (Figure 7). The Model object includes all the logic of our conceptual model, that we built, along with all the queries towards the database. The View object includes the frontend (HTML, CSS, Javascript, AJAX) and all the features that are described in Section 4.2. Finally, the Controller updates the View when the Model changes upon a user's request.

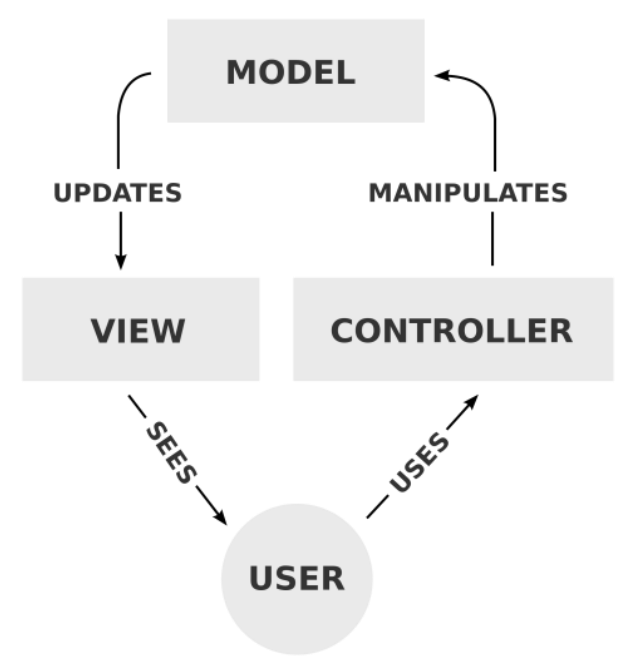

Figure 7. The Model - View - Controller (MVC) pattern 


\subsubsection{Logic}

The first page users will encounter is the Login / Sign Up Page. Once they create a new account or login in their account and the user authentication is finished, they are redirected into the main part of the environment, the Content Management System (CMS). The CMS, by accessing the database, retrieves all the information relevant to the selected game and then users can view and edit the content of the game. Figure 8 shows the component diagram of our environment's architecture and the incorporated logic.

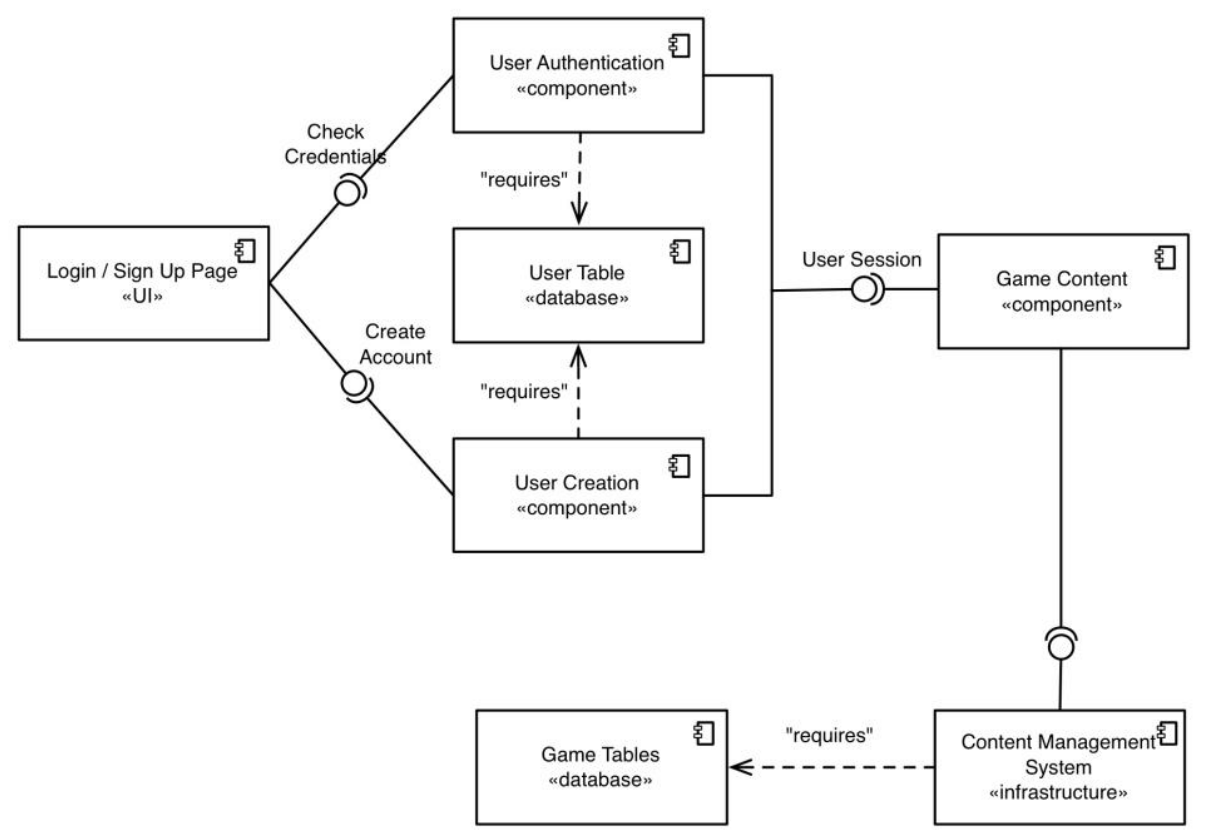

Figure 8. Component diagram of our environment's architecture

\subsection{Innovative Features and Key Design Decisions}

In our environment, we made some implementation choices that are intended to facilitate the process of creation of high-quality, useful GDDs:

- Semi-structured design environment. We wanted to take advantage of the fact that many game elements are common on all types of games but we also had in mind that game designers would want to have enough freedom to communicate the design. We therefore designed the environment in a semi-structured way, with the intention to be more flexible than fully structured environments and at the same time more rigorous than free text. An example can be seen on Figure 10, where designers can freely describe a level but the required, delivered and/or tested knowledge, along with the goals of the level, can be chosen from a predefined menu.

- Linkages of game objects. Connecting the various objects in a GDD is crucial, as demonstrated by the many relationships between the classes that exist in our conceptual model of Figure 5. Thus, we implemented these two features aiming at enabling game designers to "navigate" through the conceptual model:

$\checkmark$ Hyperlinks. In many cases, wherever we implemented free text areas, designers can choose objects that they have already created, such as goals, challenges, character or even audio files, to either mention them on the text or link them with other objects from the database. Additionally, the object is inserted as underlined text, in order to stand out from the rest of the text, and users can see all the details of the object, i.e. the description, by hovering the underlined word. An example is shown in Figure 9. The benefit of such a feature is that you can have immediately available any information regarding multiple objects, without populating the user-interface with too much text and overwhelming the users. 
$\searrow$ Dropdown Menus. The relationships between elements of Figure 5 are implemented through dropdown menus, where the list includes objects that the designer has previously created and that can be accessed by navigating our conceptual model. An example is shown in Figure 10. The usage of dropdown menus helps in two ways: (i) by only linking objects that already exist, this reduces the risk of inconsistency by referring to non-existing elements; (ii) changes in objects (e.g., renaming) are propagated automatically, without the necessity to apply the changes wherever the object is being referenced.

- No predefined flow. According to Meredith [48], decision makers on a design process face the dilemma: too much structure may stifle the creative process, while too little structure provides inadequate support. Therefore, given that we have opted for a relatively structured environment, we decided not to force designers to follow a specific sequence while designing their game (unlike the work by Marfisi-Schottman [3]). The prototype's layout resembles that of content management systems, where users can navigate freely to whichever page they want. This does not only give more freedom to designers, but also offers a known, and thus more user-friendly, user interface.

Other important features of the prototype are the progress page and export options. The progress page is a dashboard for designers that shows the status of a GDD at a glance. We have partially implemented the customization of the exported document, depending on the stakeholder for whom is intended for.

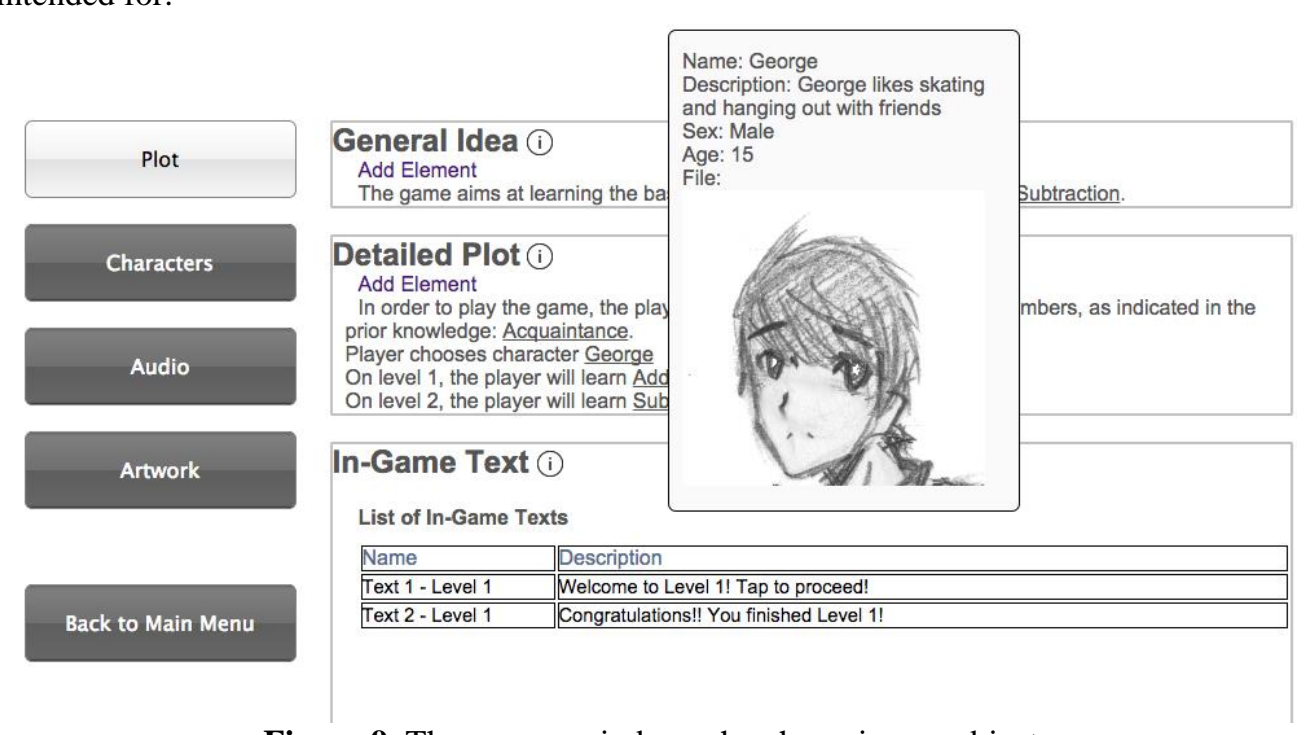

Figure 9. The pop-up window when hovering an object

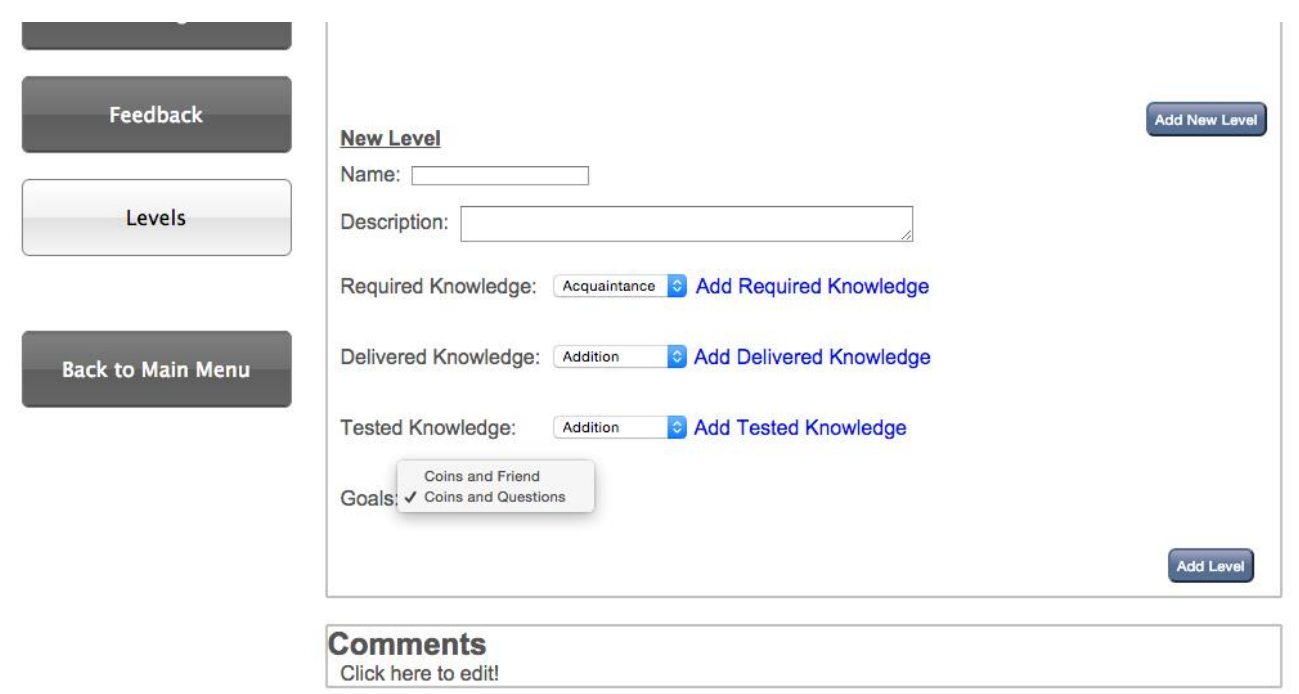

Figure 10. Levels' page 
Throughout our design process, we tried to adhere with the most important usability guidelines, especially those related with the key purpose of the environment: Consistency [49] and Learnability [50], by using standard terminology; Clarity [51], by introducing as few distractions as possible; and Relevancy [52], by keeping the concept of the environment aligned with the conceptual model.

\subsection{Example}

In order to demonstrate more efficiently the usage of the environment, below, we provide an example, which shows how the environment can be used by serious games designers. The example is of a game about basic mathematics. Due to the large number of different pages (18), we only show the game design part of the environment, since it is also the main contribution of this study.

Figure 11 shows the game mechanics, which includes the rules and the controllers of the game. The rules and the controllers, along with any other object created anywhere in the environment, can be imported in any free text area supporting the hyperlinks feature, as shown in Figure 9. In this example, Rules include the addition and the subtraction of numbers

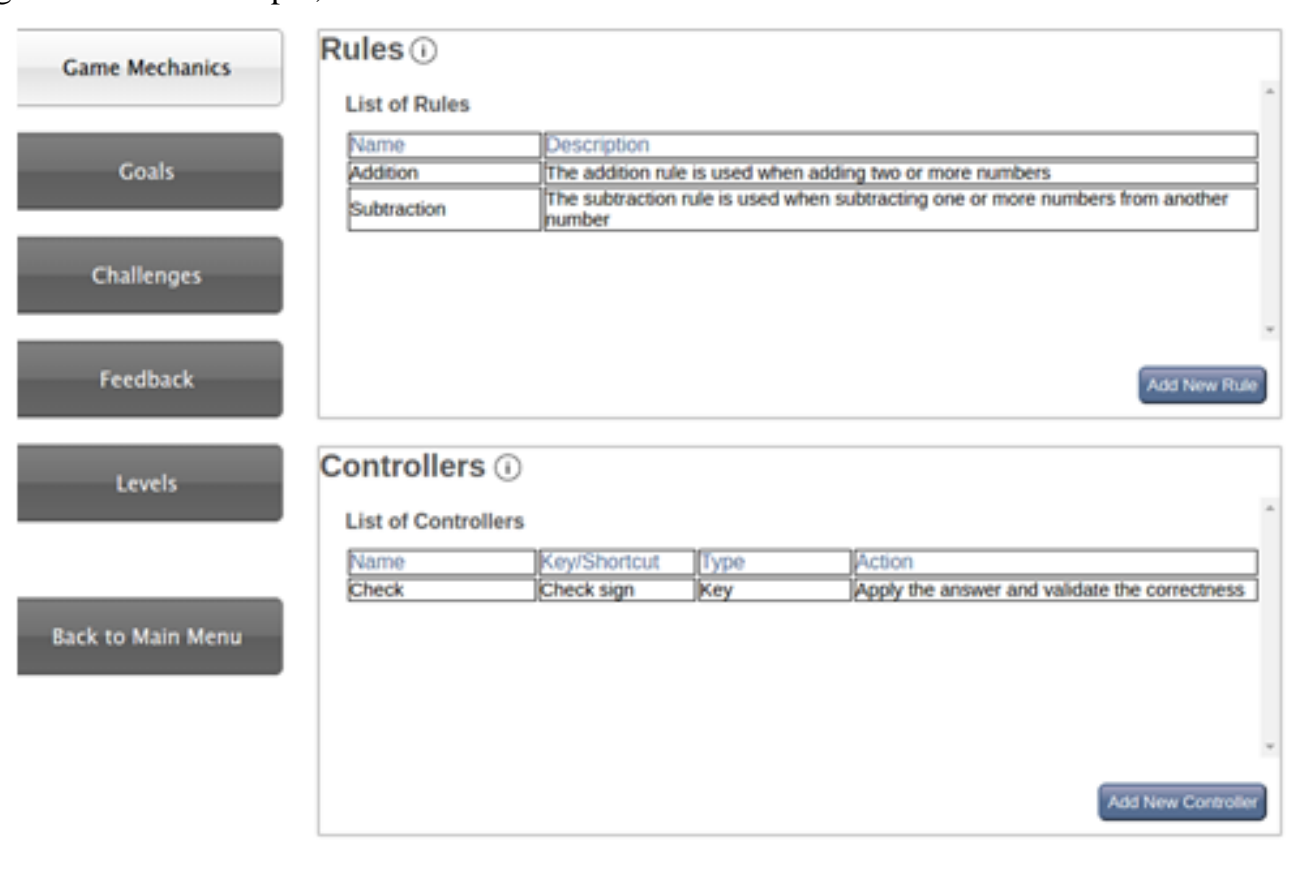

Figure 11. Game Mechanics' page

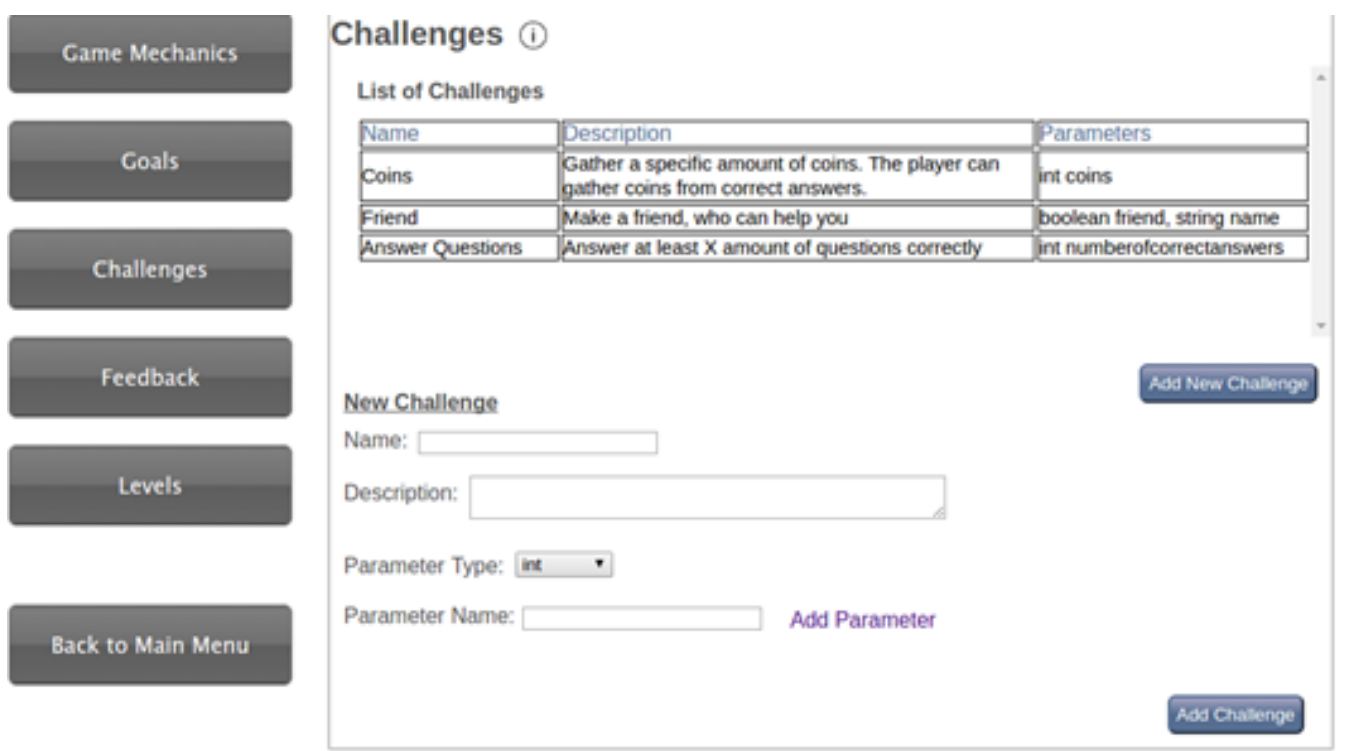

Figure 12. Challenges' page 
Figure 12 shows the Challenges of the game. Challenges are the first element of the three elements in total that are linked together. The other two elements are Goals and Levels. The connection between these three elements is as follows: Goals include one or more Challenges and Levels include one or more Goals. In other words, in order to fulfil a Goal, one or more Challenges should be successfully completed first, and in order to finish a Level, one or more Goals should be fulfilled first. Moreover, Challenges include one or more parameters that should be met, in order for the challenge to be considered successful. In this example, Challenges include the number of gathered coins, whether the main player has a friend, and the number of correctly answered questions. The advantage of using challenges with parameters is that the same challenge can be used multiple times throughout the game, e.g. at some point during the game, the player might be required to gather 50 coins, whether in another point 500 coins. Hence, the same challenge can be used with a different condition.

Figure 13 shows the Goals of the game. Goals are directly linked with both the Challenges and the Levels. In this stage, the different conditions of the challenges' parameters, which define the success of a particular challenge, are defined. In this example, Goals include a combination of challenges, like coins and friends, and coins and questions. It is shown here how one challenge can be initialized multiple times with different conditions. E.g. the challenge of gathering coins has been initialized for 100 coins, 200 coins, 500 coins, and it is used in different stages of the game.

The connection of the Levels with the Goals and the Knowledge is shown in Figure 10.

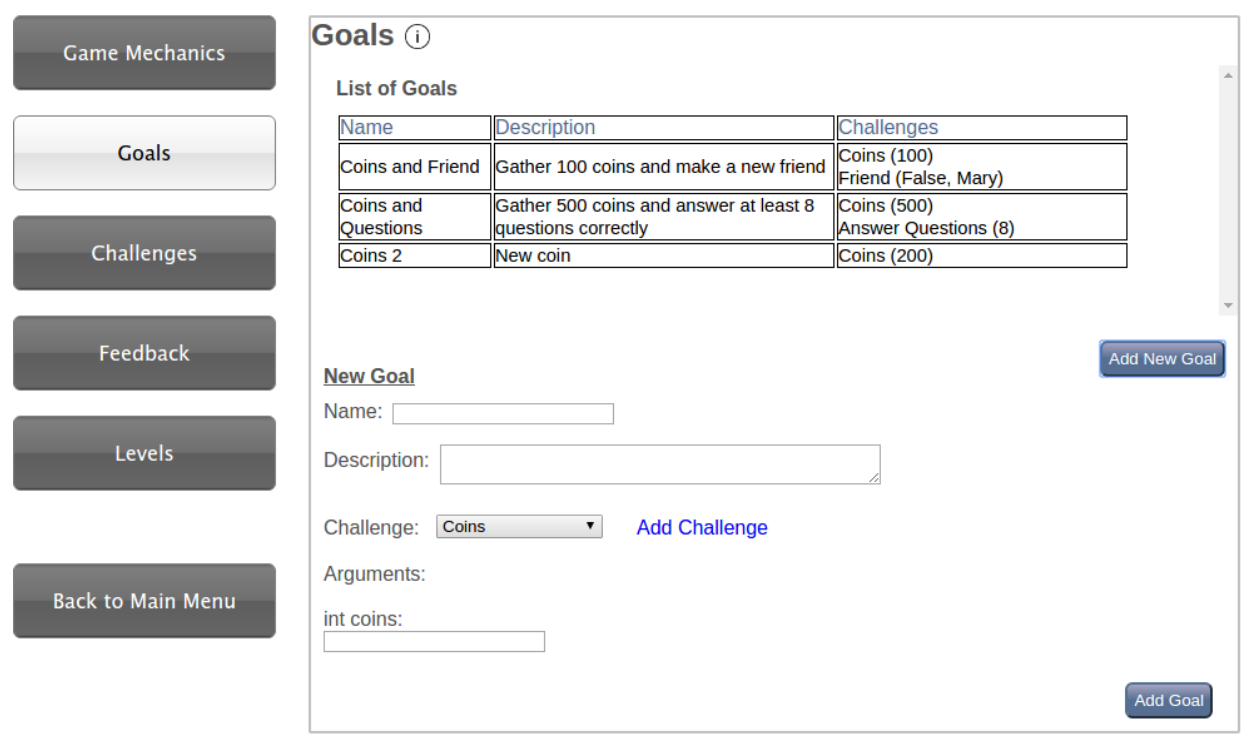

Figure 13. Goals' page

\section{Evaluation}

In this section, we describe the process we followed to evaluate our environment and the outcomes of the analysis of the obtained results. The evaluation is intended not only to understand the strengths and weaknesses of our environment (so as to improve it), but also to collect feedback concerning the conceptual model which powers the environment in a model-driven engineering fashion.

The aim of the evaluation is to check the accuracy and comprehensiveness of the conceptual model, the usability of environment, and the benefits of features like hyperlinks and dropdown menus. More generally, our wish is to obtain insights concerning the extent to which our environment and Web 2.0 technologies can help game development teams to overcome the inconsistency and the lack of updates on GDDs and the problems associated with communication within educational game development teams. 
Table 4. Project selection matrix rules.

\begin{tabular}{|c|c|c|c|}
\hline \multirow[b]{2}{*}{ ID } & \multirow[b]{2}{*}{ Question } & \multicolumn{2}{|c|}{ Experts } \\
\hline & & Market & Academic \\
\hline 1 & Are all necessary elements present? & $\mathrm{Y}: 3, \mathrm{~N}: 0$ & $\mathrm{Y}: 4, \mathrm{~N}: 1$ \\
\hline 2.1 & $\begin{array}{l}\text { Is the non-predefined flow preferable } \\
\text { to more structured flows? }\end{array}$ & $\mathrm{Y}: 2, \mathrm{~N}: 1$ & $\mathrm{Y}: 4, \mathrm{~N}: 1$ \\
\hline 2.2 & $\begin{array}{l}\text { How easy is the navigation in the } \\
\text { website? }\end{array}$ & 2.33 (sd: 0.6) & 3.8 (sd: 0.8) \\
\hline 3.1 & $\begin{array}{c}\text { How important is linking game } \\
\text { objects in a GDD? }\end{array}$ & 5 (sd: 0) & 4 (sd: 1) \\
\hline $3.2 \mathrm{a}$ & $\begin{array}{l}\text { Are dropdown menus an efficient } \\
\text { way to link game objects? }\end{array}$ & $\mathrm{Y}: 3, \mathrm{~N}: 0$ & $\mathrm{Y}: 5, \mathrm{~N}: 0$ \\
\hline $3.2 \mathrm{~b}$ & $\begin{array}{l}\text { Are dropdown menus faster than free } \\
\text { text to link game objects? }\end{array}$ & $\mathrm{Y}: 3, \mathrm{~N}: 0$ & $\mathrm{Y}: 4, \mathrm{~N}: 1$ \\
\hline $3.3 \mathrm{a}$ & $\begin{array}{l}\text { Are hyperlinks an efficient way to } \\
\text { link game objects? }\end{array}$ & $\mathrm{Y}: 3, \mathrm{~N}: 0$ & $\mathrm{Y}: 5, \mathrm{~N}: 0$ \\
\hline $3.3 \mathrm{~b}$ & $\begin{array}{l}\text { Are hyperlinks faster than free text } \\
\text { to link game objects? }\end{array}$ & $\mathrm{Y}: 3, \mathrm{~N}: 0$ & $\mathrm{Y}: 4, \mathrm{~N}: 1$ \\
\hline $3.3 \mathrm{c}$ & $\begin{array}{l}\text { How useful is it to hover over a } \\
\text { hyperlink to see an object's } \\
\text { information? }\end{array}$ & 4.67 (sd: 0.58) & 4.8 (sd: 0.45$)$ \\
\hline $4.1 \mathrm{a}$ & $\begin{array}{l}\text { How effective is the environment to } \\
\text { get a consistent GDD? }\end{array}$ & 3.67 (sd: 0.58$)$ & 3.4 (sd: 0.89 ) \\
\hline $4.1 b$ & $\begin{array}{c}\text { How effective are Web } 2.0 \\
\text { technologies to get a consistent } \\
\text { GDD? }\end{array}$ & 5 (sd: 0) & 4.2 (sd: 0.84$)$ \\
\hline $4.2 \mathrm{a}$ & $\begin{array}{l}\text { How effective is the environment to } \\
\text { keep GDDs up-to-date? }\end{array}$ & 3 (sd: 1$)$ & 3.6 (sd: 1.14$)$ \\
\hline $4.2 \mathrm{~b}$ & $\begin{array}{c}\text { How effective are Web } 2.0 \\
\text { technologies to keep GDDs up-to- } \\
\text { date? }\end{array}$ & 3.67 (sd: 1.53$)$ & 4 (sd: 1.41) \\
\hline $4.3 \mathrm{a}$ & $\begin{array}{l}\text { How effective is the environment to } \\
\text { overcome communication problems? }\end{array}$ & 3.67 (sd: 0.58$)$ & 3.8 (sd: 0.45$)$ \\
\hline
\end{tabular}

We chose to conduct our evaluation through face-to-face interviews that are conducted after demonstrating the online environment. We have defined a plan for the evaluation and have taken several decisions with regard to the conducted interviews [53]:

- Interview Type. We decided for semi-structured interviews [54] through the use of a predefined set of questions to be rated on a Likert scale or through boolean values, followed by the possibility for the interviewees to comment on their response. This protocol combines the strengths of the structured, comparable results provided by scale-based questions with flexibility and richness of feedback from the oral comments.

- Data Collection. We decided to conduct face-to-face interviews at the subjects' working place (also known as first degree data collection techniques [55]). The reasons for this decision are a) the possibility to demonstrate the environment in detail and also give the interviewees the opportunity to experiment with it, after the presentation, b) the option to verbally explain aspects of the environment when the documentation is not sufficient, c) the visual observation of the interviewees, which could provide additional feedback regarding their interaction with the environment, and d) the informal comments of the interviewees regarding aspects of the environment that would not be possible through an online questionnaire.

- Selection of Subjects. We decided to interview serious game experts from both the commercial gaming market and the academia. In total, we interviewed eight experts: three of them are working on serious game companies and five are working in academia. All of them work in the Netherlands.

The results from the individual interviews are generally positive. All the interviewees found the idea very interesting, and the feedback we received gave us insights on how representatives from both the academic and the commercial communities of games perceive the present and the 
future of game design. The results to the closed questions are shown in Table 4. A comprehensive report is available in our online appendix ${ }^{2}$.

The number of the interviewees does not allow us to make a statistically reliable generalization of the results. Nevertheless, due to the high expertise of the interviewees in serious games development, the results provide interesting information of how our environment can be adopted by academics and by professionals and can be potentially useful for the design of educational games and for further research.

Experts from both categories find that linking game objects (question 3.1) is an important feature to design serious games. Thus, an environment like ours can be of great help, by providing structure and facilitating the linkage of game objects. The interviewees reported the lack of gamespecific tools that help game designers in documenting a game; this indicates a clear potential for an environment like ours.

The most notable differences between the two expert categories are:

1. The question about the ease of navigating through the environment (question 2.2) shows significant differences between the categories: 2.33 for the market experts and 3.8 for the academic experts. This can be explained by the fact that the academic experts have better understood the prototypical nature of the environment.

2. The average difference between the potential of our environment and of Web 2.0 technologies (question 4) is greater for the market experts than for the academic experts, especially in how they help overcome problems associated with game design documents: consistency (see questions 4.1a and 4.1b), updates (see questions 4.2a and 4.2b), and communication (see questions $4.3 \mathrm{a}$ and $4.3 \mathrm{~b}$ ).

Finally, we noticed that market experts perceived issues like user experience and user interface friendliness almost as important as the actual functionality of the environment, opening a whole new area for improving our prototypical environment.

\section{Discussion}

In this paper, we presented a conceptual model of educational games and an online environment based on that model. Our long-term objective is to study whether the usage of GDDs is limited due to the lack of effective tools or is rather due to the way educational games are developed. The preliminary evaluation that we conducted, which involved interviews with serious games experts, confirmed the absence of game-specific design tools, and has shown a positive attitude towards the potential benefit of a web, model-driven environment to mitigate the problems of GDD-based game design.

Our evaluation suffers from threats towards the validity affecting our evaluation. Internal validity is threatened by the use of a mixed approach that combines boolean questions with Likert scale questions: for homogeneity, we should have employed the same type of scale. Moreover, we have mostly demonstrated the tool, instead of letting the interviewees use it. Some of the questions are subject to confirmatory bias, i.e., the tendency of people of agreeing with the statements/questions. In terms of external validity, we have conducted a study with a small number of interviewees, all of which from the same geographic area. Moreover, there are threats concerning the credibility of the results, for we employed a custom questionnaire as opposed to validated questions.

This paper simply paves the way for future research in the field. The conceptual model can be further researched upon to identify any missing core element of educational games. These changes would obviously have to be mapped into the model-based design environment; maintaining this mapping could be facilitated by using a model-driven engineering development environment. Moreover, linking game mechanics with learning models, as depicted on the LM-GM model [56], will provide designers with a "dictionary" for adjusting the game mechanics to the learning objectives of the game. In the same spirit, the environment can be modified to produce all the necessary UML diagrams, as described in the ATMSG model [57], thus helping collaboration among the different stakeholders. The user interface and look-and-feel of the prototype can be greatly improved, especially in order to enable longitudinal studies on the effectiveness of our approach. Finally, case studies are necessary to fully validate our environment. 


\section{References}

[1] Zyda M., "From visual simulation to virtual reality to games," Computer (Long. Beach. Calif)., vol. 38, no. 9, pp. 25-32, 2005. http://dx.doi.org/10.1109/mc.2005.297

[2] Takahashi D., "With a mobile boom, learning games are a $\$ 1.5 \mathrm{~B}$ market headed toward $\$ 2.3 \mathrm{~B}$ by 2017 (exclusive) | GamesBeat | Games | by Dean Takahashi," 2013. [Online]. Available: http://venturebeat.com/2013/08/16/with-a-mobile-boom-learning-games-are-a-1-5b-marketheaded-toward-2-3b-by-2017-exclusive/. [Accessed: 03-Jun-2015].

[3] Marfisi-Schottman I., George S., and Tarpin-Bernard F., "Tools and methods for efficiently designing serious games," in Proceedings of the 4th Europeen Conference on Games Based Learning ECGBL, 2010, pp. 226-234.

[4] Sundström Y., "Game design and production: frequent problems in game development." 2013.

[5] Brown D. M., Communicating design: Developing web site documentation for design and planning, vol. 39, no. 1. 2010.

[6] Bethke E., Game development and production. Wordware Publishing, Inc., 2003.

[7] Wand Y., Storey V. and Weber R., "An ontological analysis of the relationship construct in conceptual modeling," ACM Trans. Database Syst., vol. 24, no. 4, pp. 494-528, 1999. http://dx.doi.org/10.1145/331983.331989

[8] Rousseau, Emile, ou de l'éducation, introduction et annotation conceptuelle par André Charrak, Paris, Flammarion, 2009.

[9] Piaget J., "Part I: Cognitive development in children: Piaget development and learning," J. Res. Sci. Teach., vol. 2, no. 3, pp. 176-186, 1964. http://dx.doi.org/10.1002/tea.3660020306

[10] Vygotsky L., The Collected Works of LS Vygotsky: Problems of the theory and history of psychology. Springer Science \& Business Media, 1997.

[11] Csikszentmihalyi M., Rathunde K., and Whalen S., Talented teenagers: The roots of success and failure. Cambridge University Press, 1997.

[12] Whitaker D. and Graham C., "Neighborhood \& family effects on learning motivation among urban African American middle school youth," J. Child Fam. Stud., vol. 21, no. 1, pp. 131138, 2012. http://dx.doi.org/10.1007/s10826-011-9456-1

[13] Ormrod J., "How motivation affects learning and behavior," 2010.

[14] Csikszentmihalyi M., Flow: The psychology of optimal experience, vol. 41. HarperPerennial New York, 1991.

[15] Mace C., The psychology of study. Penguin, 1968.

[16] Chance P., Learning and behavior. Nelson Education, 2013.

[17] Durkheim E., "The division of labor in society," J. des Econ., p. 211, 1884.

[18] Jung C. G, "The Archetypes and the Collective Unconscious," Twent. Century Crit. Major Statements, ed. William J. Handy Max West-brook (New Delhi, Light Life Publ. 1974), p. 205, 1974.

[19] Aristotle, Poetics, in "The basic works of Aristotle", edited by Richard McKeon, New York: Random House, 1941.

[20] Malone T. W., "What makes things fun to learn? Heuristics for designing instructional computer games," in Proceedings of the 3rd ACM SIGSMALL symposium and the first SIGPC symposium on Small systems, 1980, pp. 162-169. http://dx.doi.org/10.1145/800088.802839

[21] Garris R., Ahlers R., and Driskell J. E., "Games, motivation, and learning: A research and practice model," Simul. Gaming, vol. 33, no. 4, pp. 441-467, 2002. http://dx.doi.org/10.1177/1046878102238607

[22] Salen K. and Zimmerman E., Rules of play: Game design fundamentals. MIT press, 2004.

[23] Baldwin M., "Game design document outline," 2005. [Online]. Available: http://ddijogos.xpg.uol.com.br/Baldwin_Game_Design_Document_Template.pdf. [Accessed: 04-Jun-2015].

[24] Winn B., "The design, play, and experience framework," Handb. Res. Eff. Electron. gaming Educ., vol. 3, pp. 1010-1024, 2008.

[25] Hunicke R., LeBlanc M., and Zubek R., "MDA: A formal approach to game design and game research," in Proceedings of the AAAI Workshop on Challenges in Game AI, 2004, vol. 4.

[26] Mitgutsch K. and Alvarado N., "Purposeful by design?: a serious game design assessment framework," in Proceedings of the International Conference on the Foundations of Digital Games, 2012, pp. 121-128. http://dx.doi.org/10.1145/2282338.2282364 
[27] Amory A. and Naicker K., "The use of computer games as an educational tool: Identification of appropriate game types and game elements," Br. J. Educ. Technol., vol. 30, no. 4, pp. 311321, 1999. http://dx.doi.org/10.1111/1467-8535.00121

[28] Aleven V., Myers E., Easterday M., and Ogan A., "Toward a framework for the analysis and design of educational games," in Proceedigns of the IEEE International Conference on Digital Game and Intelligent Toy Enhanced Learning (DIGITEL), 2010, pp. 69-76. http://dx.doi.org/10.1109/digitel.2010.55

[29] Callele D., "Requirements engineering and the creative process in the video game industry," in Proceedings. 13th IEEE International Conference on Requirements Engineering, 2005. http://dx.doi.org/10.1109/RE.2005.58

[30] Callele D., "Emotional requirements in video games," in 14th IEEE International Conference on Requirements Engineering, 2006. http://dx.doi.org/10.1109/RE.2006.19

[31] Draper S., "Analysing fun as a candidate software requirement," Pers. Technol., vol. 3, no. 3, pp. 117-122, 1999. http://dx.doi.org/10.1007/BF01305336

[32] Greer M. and Levine E., "Enhancing creative performance in college students," J. Creat. Behav., vol. 25, no. 3, pp. 250-255, 1991. http://dx.doi.org/10.1002/j.21626057.1991.tb01377.x

[33] Nijholt A., Bos D. P.-O., and Reuderink B., "Turning shortcomings into challenges: Brain-computer interfaces for games," Entertain. Comput., vol. 1, no. 2, pp. 85-94, 2009. http://dx.doi.org/10.1016/j.entcom.2009.09.007

[34] Juul J., "Without a goal: on open and expressive games," Videogame, Play. text, pp. 191-203, 2007.

[35] Vockell E., "Educational psychology: A practical approach,” Purdue Univ. Calumet, on-line B., 2004.

[36] Hawkes M., "Effects of task repetition on learner motivation," in JALT2009 Conference Proceedings, 2009.

[37] "Dialogue." Oxford Dictionary of English (3 ed.). 2010. Oxford University Press.

[38] Yamada M., Fujisawa N., and Komori S., "The effect of music on the performance and impression in a video racing game," J. Music Percept. Cogn., vol. 7, no. 2, pp. 65-76, 2001.

[39] Ju E. and Wagner C., "Personal computer adventure games: Their structure, principles, and applicability for training," ACM SIGMIS Database, vol. 28, no. 2, pp. 78-92, 1997. http://dx.doi.org/10.1145/264701.264707

[40] Asgari M. and Kaufman D., "Relationships among computer games, fantasy, and learning," in Proceedings of the 2nd International Conference on Imagination and Education, 2004.

[41] Harter S., "A new self-report scale of intrinsic versus extrinsic orientation in the classroom: Motivational and informational components.," Dev. Psychol., vol. 17, no. 3, p. 300, 1981. http://dx.doi.org/10.1037/0012-1649.17.3.300

[42] Ermi L and Mäyrä F., "Fundamental components of the gameplay experience: Analysing immersion," Worlds Play Int. Perspect. Digit. games Res., vol. 37, 2005.

[43] McKeon R. and Levinson J., "Poetics. The Basic Works of Aristotle." Random House New York, 1941.

[44] Maslow A., "A theory of human motivation," Psychol. Rev., vol. 50, no. 4, p. 370, 1943. http://dx.doi.org/10.1037/h0054346

[45] Piage J. t, "Cognitive development in children: The Piaget papers," in Piaget rediscovered: a report of the conference on cognitive studies and curriculum development, 1964, pp. 6-48.

[46] Guthrie E., The psychology of learning. 1952.

[47] Schmidt D. C., "Guest editor's introduction: Model-driven engineering," Computer (Long. Beach. Calif)., vol. 39, no. 2, pp. 25-31, 2006. http://dx.doi.org/10.1109/mc.2006.58

[48] Meredith R., "Creative freedom and decision support systems," in Creativity and Innovation in Decision Making and Decision Support, 2006, pp. 30-46.

[49] Nielsen J., "Enhancing the explanatory power of usability heuristics," in Proceedings of the SIGCHI conference on Human Factors in Computing Systems, 1994, pp. 152-158.

[50] Lewis J. R. and Sauro J., "The factor structure of the system usability scale," in Human Centered Design, Springer, 2009, pp. 94-103.

[51] Palmer J. W., "Web site usability, design, and performance metrics," Inf. Syst. Res., vol. 13, no. 2, pp. 151-167, 2002. http://dx.doi.org/10.1287/isre.13.2.151.88

[52] Koohang A., "Expanding the concept of usability," Informing Sci., vol. 7, pp. 129-141, 2004. 
[53] Wohlin C., Runeson P., Höst M., Ohlsson M. C., Regnell B., and Wesslén A., Experimentation in software engineering. Springer Science \& Business Media, 2012. http://dx.doi.org/10.1007/978-3-642-29044-2

[54] Robson C., Real world research: A resource for social scientists and practitioner-researchers, vol. 2. Blackwell Oxford, 2002.

[55] Lethbridge T., Sim S., and Singer J., "Studying software engineers: Data collection techniques for software field studies," Empir. Softw. Eng., vol. 10, no. 3, pp. 311-341, 2005. http://dx.doi.org/10.1007/s10664-005-1290-x

[56] Arnab S., Lim T., and Carvalho M., "Mapping learning and game mechanics for serious games analysis," Br. J. Educ. Technol., vol. 46, no. 2, pp. 391-411, 2015. http://dx.doi.org/10.1111/bjet.12113

[57] Carvalho M., Bellotti F., and Berta R., "An activity theory-based model for serious games analysis and conceptual design," Comput. Educ., vol. 87, pp. 166-181, 2015. http://dx.doi.org/10.1016/j.compedu.2015.03.023 